\title{
Lead Site Dorsal
}

National Cancer Institute

\section{Source}

National Cancer Institute. Lead Site Dorsal. NCI Thesaurus. Code C135391.

A bipolar electrocardiog ram limb lead which records the voltage between the negative electrode behind the right ear near the right mastoid process and the positive electrode on the hindquarters proximal to the sacrum. (CDISC) 